DOI: 10.11606/issn.2318-8855.v6i6p243-261

\title{
Tempo e Tempos no Mundo Bizantino do Século XIII: Análise dos Epítomes Éticos sobre a Instabilidade da Vida, de Teodoro II Láscaris ${ }^{1}$
}

Hermano do Amaral Pinto Neto*

Resumo: O século XIII bizantino foi um período de grandes crises e transformações, tanto na esfera política quanto na esfera cultural. A tomada de Constantinopla pela Quarta Cruzada em 1204 e a subsequente fragmentação do império apresentou desafios materiais e cognitivos sem precedentes para o mundo grego bizantino, na medida em que sua unidade política se pulveriza e sua vida cultural, centrada em torno da capital, precisa se adaptar à nova realidade de fragilidade. Os Epítomes Éticos sobre a Instabilidade da Vida foram compostos nesse contexto por Teodoro II Láscaris, controverso imperador de Niceia de 1254 a 1258, que nos legou uma vasta produção intelectual na área de filosofia política. Os ensaios foram escritos no período de luto de Láscaris por sua falecida esposa, Elena da Bulgária. Neles, o autor aborda diversas temáticas sobre a futilidade e efemeridade da existência humana, sob o viés do tempo como agente corruptor e destruidor. Neste artigo, examinamos algumas das ricas noções de tempo presentes nos ensaios, desde a relação conturbada do autor com a morte até as severas implicações escatológicas da corrupção da glória imperial, apontada pelo mesmo, passando também por noções bizantinas de História, amor, profano, sagrado, espiritualidade e existência. Verificamos a significativa influência do pensamento parmenidiano e aristotélico na obra de Láscaris e, portanto, na intelligentsia nicena da época. Seu círculo de letrados foi claramente influenciado pelo legado intelectual da Antiguidade

\footnotetext{
1 Agradeço ao Prof. Dr. João Paulo Garrido Pimenta, do Departamento de História da Universidade de São Paulo, sob cuja égide e conselhos, na disciplina História Social do Tempo, o embrião deste artigo foi composto. Também

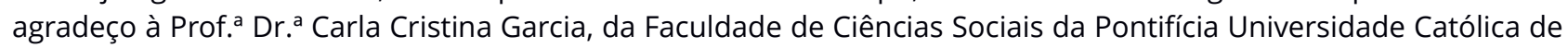
São Paulo, que foi a primeira a me ensinar a redigir um texto acadêmico.

*Bacharel em Relações Internacionais pela Pontifícia Universidade Católica de São Paulo, graduado em 2016, e estudante de segundo ano de História na Universidade de São Paulo. E-mail de contato: hermano.pinto@usp.br
} 
clássica, presente, sobretudo, no mundo bizantino, mas também mantém uma moral e preocupações essencialmente cristãs.

Palavras-Chave: História Social do Tempo, Teodoro II Láscaris, Epítomes Éticos sobre a Instabilidade da Vida, Império de Niceia, tempo bizantino

\section{Obra, autor e tema}

Os Epítomes Éticos sobre a Instabilidade da Vida², ou simplesmente Epítomes Éticos, foram compostos pelo imperador bizantino Teodoro II Láscaris em meados do século XIII, provavelmente na primavera ou verão de 1252 (ANGELOV, 2012, p. 241). A pequena obra filosófica é uma coletânea de doze curtos, porém, intensos ensaios nos quais Láscaris discursa dramaticamente sobre a efemeridade de seu mundo e, portanto, da existência humana. A essência dos Epítomes Éticos é de que nada é verdadeiramente permanente no mundo humano, sendo que todas as coisas são corrompidas com o passar do tempo e estão fundamentalmente condenadas ao fardo da não existência. Assim, em última análise, nada teria real importância, exceto as poucas coisas que prevaleceriam frente às forças destrutivas do tempo - para Láscaris, em suma, a alma imortal e o intelecto.

O autor dos Epítomes Éticos, Teodoro II Ducas Láscaris, reinou como "imperador dos romanos" (Acropolites apud: MACRIDES, 2007, p. 144) de 1254 até a sua morte em 1258, aproximadamente aos seus trinta e seis anos. No seu reinado, no entanto, o império era apenas uma sombra débil do que já fora - Láscaris reinou durante o período de exílio dos bizantinos no chamado império de Niceia, a mais formidável das unidades políticas sucessoras do velho império, fragmentado após a tomada de Constantinopla pela Quarta

2 Fonte traduzida, comentada e publicada em: ANGELOV, Dimiter. "The Moral Pieces by Theodore II Laskaris". Dumbarton Oaks Papers, pp. 237-269, n 65-66, 2011-2012. A tradução de Angelov do original grego para o inglês será a principal base deste artigo. A fonte foi intitulada Moral Pieces por Angelov. Devido à dificuldade de tradução mantendo o sentido desse título do inglês para o português, preferimos utilizar uma outra tradução do título original (Ethical Epitomes), reproduzida pelo próprio Angelov em: _. Imperial Ideology and Political Thought in Byzantium, 1204-1330. New York: Cambridge University Press, 2007, p. 215. 
Tempo e Tempos no Mundo Bizantino do Século XIII: Análise dos Epítomes Éticos sobre a Instabilidade da Vida, de Teodoro II Láscaris

Cruzada em $1204^{3}$. Apesar de sua vida curta e turbulenta, "Láscaris foi um escritor extremamente prolífico", em cuja obra e teoria político-filosófica "tentou justificar ideologicamente suas políticas anti-aristocráticas radicais", produzindo uma "síntese de ideias verdadeiramente extraordinária" (ANGELOV, 2007, pp. 215, 204, 250). Com efeito, devido à sua sumária negação de padrões de comportamento adequados a um soberano e seu favorecimento de uma razão puramente de Estado na atuação política, sobretudo interna, as teses inovadoras de Láscaris já foram comparadas com as de Nicolau Maquiavel, embora esta analogia não deva ser exagerada (ibidi, p. 251).

O principal objetivo político de Láscaris certamente era dissolver o poder dinástico das grandes famílias do Império Bizantino, sua principal e agressiva política imperial em quatro anos de reinado. Entretanto, os Epitomes Éticos são uma exceção em sua ampla produção literária, apesar da existência de passagens como "a nobreza não é medida pelo sangue, mas pela virtude"4 (ANGELOV, 2012, pp. 264-265), que são alguns exemplos de elementos fundamentais de sua filosofia política. Pelo contrário, os Epítomes Éticos foram escritos logo após a morte prematura de sua esposa Elena da Bulgária enquanto Láscaris estava de luto pela mulher que afirma ter amado genuinamente, isolado em sua aflição no Palácio de Nymphaeum ${ }^{5}$. Nos parece sensato afirmar que seu luto contribuiu para o tom melancólico e dramático dos Epítomes Éticos, sobretudo evidente no último ensaio, no qual Láscaris dolorosamente escreve:

E você, meu corpo inteiro com suas partes interiores e exteriores, obtenha o sofrimento da morte, fique no Hades junto com sua alma gêmea para compartilhar sua dor. Pois um vínculo de amor incomparável nos fazia mais feliz do que todas as pessoas, mas a mão ladra e cruel de Hades cortou esse vínculo impiedosamente. O que eu deveria sofrer? Pedirei nada mais do que o

3 Os bizantinos reconquistariam Constantinopla apenas em 1261, sob o comando de Miguel VIII Paleólogo, arquiinimigo de Teodoro II, que usurpou a coroa de seu jovem filho, João IV Láscaris.

4 No original: "For nobility is measured not by blood, but by the way of virtue".

5 Residência de verão dos Lascáridas, próxima de Esmirna (atual Izmir). Posteriormente, Teodoro II Láscaris viria a elaborar um pedido de desculpas para todos aqueles que o aconselhavam a se casar em segundas núpcias, pois ele se recusava a desposar novamente. 
fim da minha vida. Isso não pode acontecer de nenhuma outra maneira do que descer às moradas da morte e aceitar a punição de Hades e a aflição da diminuição, porque fui privado da minha vida, do espírito da minha alma e da essência do meu coração, e da salvação da minha vida, tanto espiritual quanto $\operatorname{corporal}^{6}($ ibidi, p. 269).

Segundo o texto, o amor que o autor sentia por sua falecida esposa o perturbava amplamente. Ele até afirma que preferiria morrer para se juntar a sua "alma gêmea" no Hades, uma espécie de limbo das almas, entre a vida, o julgamento e o paraíso, não permitindo que ela sofresse a diminuição sozinha. Como já mencionado, o tempo aparece como a grande força destruidora e corruptora de tudo o que não é permanente; "o tempo passa, vidas se extinguem"7 (ibidi, p. 265) lamenta Láscaris em seu décimo ensaio, uma clara alusão ao destino de Elena Lascarina. Porém, enquanto Láscaris pode ter inovado em sua filosofia política, a equiparação do tempo com a corrupção não é uma ideia original sua. Na primeira metade do século XII, a princesa e historiadora Ana Comnena abre a sua famosa obra Alexíada com a seguinte proposta:

O tempo, em seu irresistível e incessante fluxo, carrega tudo o que foi criado em sua corrente, e tudo afoga nas profundezas da obscuridade, não importando se fosse indigno de menção, ou muito digno e importante, e assim, como diz o escritor de tragédias, "ele traz da escuridão todas as coisas para nascerem, e todas as coisas nascidas são submergidas pela noite."

Mas a narrativa da história forma um baluarte muito forte contra a corrente do tempo, e até certo ponto restringe seu irresistível fluxo, e, de todas as coisas feitas nela, tantas quanto a história tomou conta, ela as protege e unifica, e não permite que escapolem para o abismo do esquecimento (COMMENA, 2000, p.2). ${ }^{8}$

\footnotetext{
6 No original: "And you, my whole body with its inner and outer parts, gain the suffering of death, dwell in Hades together with your soul mate in order to share her pain. For a bond of incomparable love made us happier than all people, but the thieving and cruel hand of Hades cut the bond mercilessly. What should I suffer? I will ask for nothing but the end of my life. This cannot happen in any other way but by descending into the abodes of death and accepting the punishment of Hades and the affliction of diminution, because I have been deprived of my life, my soul's spirit and heart's substance, and the salvation of my life, both spiritual and corporal."
}

7 No original: "Time passes, lives become extinct".

8 No original: "Time in its irresistible and ceaseless flow carries along on its flood all created things, and drowns them in the depths of obscurity, no matter if they be quite unworthy of mention, or most noteworthy and important, and thus, as the tragedian says, "he brings from the darkness all things to the birth, and all things born envelops in the night." But the tale of history forms a very strong bulwark against the stream of time, and to some 
Tempo e Tempos no Mundo Bizantino do Século XIII: Análise dos Epitomes Éticos sobre a Instabilidade da Vida, de Teodoro II Láscaris

O tempo, mais uma vez, surge como uma força destruidora. No trecho, entretanto, o tempo não apenas destrói o mundo material, como Láscaris lamenta, mas também a própria memória deste - é uma espécie de dupla inexistência, na qual mesmo a lembrança do que já existiu uma vez é corrompida e extinguida com a passagem do tempo. Notavelmente, Comnena relaciona a História como um instrumento para a prevenção desse esquecimento, sendo a única esperança para a perpetuação da memória. Também é digna de atenção a analogia do tempo com o fluxo de um rio, que é uma das representações simbólicas mais prevalentes do tempo na literatura grega e bizantina, e também aparece, embora com modificações, no segundo ensaio dos Epítomes Éticos, no qual o autor navega no perigoso "mar da vida"' (ANGELOV, 2012, p. 256), todavia sua embarcação é destruída pela corrupção do tempo.

Ana Comnena foi uma exceção em um mundo dominado por autores homens. Como filha primogênita e porfirogênita ${ }^{10}$ de Alexios I Comneno (r. 1081-1118) e uma pretendente ao manto imperial, ela gozou da melhor educação e erudição ao longo de sua vida. Para os bizantinos isso incluía o estudo de historiadores da Antiguidade como Heródoto e Tucídides (ANGOLG, WHITBY, 2008, p. 838), de quem, por exemplo, Comnena e outros historiadores como Miguel Psellos e Nicetas Choniates parecem ter herdado a preocupação pelo passado recente não documentado. "Originalmente, a tarefa do historiador grego não era explicar o presente em termos do passado, mas assegurar que as ações e os eventos significativos não fossem esquecidos no futuro" (WHITROW, 1993, p. 59), característica que fica ainda mais clara quando Comnena descreve a função social da História em seguida:

Pretendo nesta minha obra recontar os feitos do meu pai, pois eles certamente não deveriam ser perdidos para o silêncio, ou levados embora,

extent checks its irresistible flow, and, of all things done in it, as many as history has taken over, it secures and binds together, and does not allow them to slip away into the abyss of oblivion."

9 No original: "Sea of life".

10 Do grego Porphyrogennetos, "nascido na púrpura". Título conferido aos filhos e filhas de um imperador. 
assim, na corrente do tempo para dentro do mar do esquecimento [...]. Estes feitos irei relatar não para exibir minha proficiência em letras, mas para que questões de tal importância não sejam deixadas não documentadas para gerações futuras. Pois mesmo o maior dos feitos, se não for preservado por acaso em palavras escritas e passado adiante para a recordação, é extinto na obscuridade do tempo (COMNENA, 2000, p. 2). ${ }^{11}$

A equação do tempo com o esquecimento tampouco é especificidade de Teodoro II Láscaris e Ana Comnena. No século XIV, o historiador bizantino Nicéforo Gregoras critica o desprezo de Andrônico III Paleólogo pelas cerimônias da corte, as quais "corriam o risco de afundar nas profundezas do esquecimento; após a passagem do tempo e o falecimento daqueles que tinham esse conhecimento, seria difícil que os seus sucessores soubessem as coisas necessárias"12 (Gregoras apud: MACRIDES, MUNITIZ, ANGELOV, 2013, p. 2), levando a ordem imperial à decadência.

Ainda mais significativa é a História de Jorge Acropolites. Mais do que um simples historiador, Acropolites foi professor, tutor e amigo íntimo de Teodoro II Láscaris, embora tenha se juntado ao regime dos Paleólogos após a morte de seu patrono e ex-aluno. "A utilidade da história já foi definida pelos nossos predecessores"13 (apud MACRIDES, 2007, p. 105), elucida Acropolites, provavelmente se referindo à vasta linha de historiadores e cronistas que o antecederem e aprenderam a escrever História em grego com Heródoto e Tucídides (Ana Comnena, entre eles). Acropolites elabora:

Em todo caso, o autor deve escrever nem com favorecimento e nem com malícia, nem pelo ódio ou pela boa vontade, mas pelo bem da história somente e, assim, para que o que foi feito por alguns, seja bom ou ruim, não

\footnotetext{
11 No original: "I intend in this writing of mine to recount the deeds done by my father for they should certainly not be lost in silence, or swept away, as it were, on the current of time into the sea of forgetfulness [...] These deeds I am going to relate, not in order to show off my proficiency in letters, but that matters of such importance should not be left unattested for future generations. For even the greatest of deeds, if not haply preserved in written words and handed down to remembrance, become extinguished in the obscurity of silence."
}

12 No original: "Were in danger of sinking into the depths of oblivion; after the passing of time and passing of those who had knowledge it would be difficult for their successors to know the necessary things"

13 No original: "The usefulness of history has already been defined by our predecessors" 
Tempo e Tempos no Mundo Bizantino do Século XIII: Análise dos Epítomes Éticos sobre a Instabilidade da Vida, de Teodoro II Láscaris

seja relegado para as profundezas do esquecimento que o tempo costuma produzir (ibidi, p. 105). ${ }^{14}$

Como na Alexíada, a História de Jorge Acropolites também tem em sua abertura o esclarecimento da função social da História, no entendimento do autor. Mais uma vez, a concepção herdada da historiografia grega clássica, integrante de boa parte da mentalidade e erudição bizantina, é empregada. Essa passagem de Acropolites nos é especialmente relevante não só graças à sua contemporaneidade com os Epítomes Éticos, mas também pela relação de amizade e aprendizagem entre o autor e Teodoro II Láscaris - é a prova necessária de que os Epítomes Éticos, muito mais do que um panegírico melancólico a Elena da Bulgária, são uma porta de entrada rica para a mentalidade da elite bizantina e as suas relações com os tempos históricos.

Antes de prosseguir, seria proveitoso notar aqui que a experiência bizantina em suas formas de viver o tempo esteve intimamente ligada à sua forma de organização temporal e cronológica. Adeptos do calendário juliano, a principal especificidade bizantina era a sua divisão do calendário em indicções, ciclos de quinze anos cada, originalmente para propósitos fiscais - de fato, a data inicial de uma indicção, $1^{\circ}$ de setembro, já se tornara o ano novo litúrgico ao redor do século X. Além disso, mais crucialmente, os bizantinos organizaram seu calendário a partir do ano da Criação do mundo (Anno Mundi), em vez do Anno Domini ocidental, tendo seu ano inicial em 5510 a.C. do nosso calendário. Também é importante notar que seguiam a teleologia cristã básica de um julgamento final, o qual aconteceria em 7000 AM (1492 AD), quando até mesmo os imperadores seriam julgados perante Deus (BRYER, 2008). As implicações escatológicas do tempo litúrgico bizantino ainda serão discutidas no decorrer deste artigo.

Nossa intenção é sucintamente examinar algumas das noções de tempo presentes nos Epítomes Éticos. O objetivo não se limita a analisar somente a influência do cristianismo e da

14 No original: "At all events, the author ought to write neither with favour nor with malice, nor out of hatred or goodwill, but for the sake of history alone and so that what has been done by some, whether it be good or bad, is not relegated to the depths of oblivion which time is wont to produce." 
teologia ortodoxa no pensamento de Teodoro II Láscaris, mas também do legado da Antiguidade greco-romana clássica, de qual cálice os bizantinos (ou romanos, como se auto designavam) beberam mais do que qualquer sociedade medieval. "Eternos adeptos da compartimentalização, os bizantinos traçaram uma linha clara e bastante reveladora entre a literatura da Grécia antiga, que chamavam de Saber Exterior, e a literatura cristã, o Saber Interior" (WELLS, 2011, p. 60) coloca Colin Wells, que provoca: "Atenas faiscava em um dos lados da consciência bizantina, Jerusalém brilhava suavemente do outro" (ibidi, p. 60). Resta saber se a forma pela qual o tempo é vivido e experimentado por Teodoro II Láscaris nos Epítomes Éticos segue esta divisão, ou mesmo se esses dois tempos históricos diferentes se confundem entre si.

\section{Os tempos dos Epítomes Éticos}

De antemão, é possível identificar na morte uma das principais temáticas temporais abordadas por Láscaris, senão a principal. O próprio Angelov afirma que os Epítomes Éticos "são um raro exemplo de uma obra literária e filosófica medieval na qual um marido enlutado lamenta a morte de sua esposa" (ANGELOV, 2012, p. 237), o que é especialmente evidente na passagem em que Láscaris declama sua descida ao Hades para se juntar a Elena, no último ensaio. O tema da morte está presente logo no primeiro dos doze ensaios produzidos pelo imperador, que discorre sobre a mortalidade dos humanos e a contraposição entre a virtude e o vício corruptor da alma. Mais importante, ele reconhece a existência de Deus e, portanto, do Julgamento Final, mas argumenta que "há julgamento até antes da chegada do Juiz Justo e Sua decisão"15 (ibidi, p.254). Para Láscaris, em seu primeiro ensaio, esse julgamento se apresenta como a corrupção da alma pelo prazer e pelo materialismo: "a alma se aproxima da destruição e gira em círculos, imitando a inconstância do tempo"16 (ibidi, p.255).

\footnotetext{
15 No original: "There is judgment even before the arrival of the Just Judge and His decision".

16 No original: "The soul nears destruction and revolves in circles imitating the inconstancy of time". A imagem da inconstância do tempo como sendo circular é particularmente curiosa nessa passagem, já que a tradição platônica, a qual Láscaris certamente conhecia e buscava reproduzir, associa a circularidade do tempo a um tempo eterno e constante - um tempo sagrado frente ao tempo profano que nosso autor abomina.
} 
Tempo e Tempos no Mundo Bizantino do Século XIII: Análise dos Epítomes Éticos sobre a Instabilidade da Vida, de Teodoro II Láscaris

A teologia bizantina sobre a vida após a morte nunca foi tão elaborada quanto no cristianismo ocidental (MARINIS, 2017, p. 2), mas havia diretrizes herdadas do Velho Testamento. Apesar de nunca terem desenvolvido um conceito exatamente como o purgatório latino, os bizantinos reconheciam um estado intermediário da alma entre a morte e o Julgamento Final. Era uma adaptação do Sheol judaico, traduzido pela Septuaginta ${ }^{17}$ como o Hades. O bispo bizantino Jorge Bardanes, contemporâneo de Láscaris, acreditava que as almas dos mortos "residiam em locais temporários, onde elas experimentavam uma amostra de suas punições ou recompensas de vários tipos, presumivelmente alocadas de acordo com sua conduta em vida" (ibidi, p. 1).

O Hades é mencionado três vezes nos Epítomes Éticos, todas no último ensaio. Ao contrário da apresentação mais positiva de Bardanes, o Hades aparece nos Epítomes Éticos sobretudo como um local de punição. A alma de Elena Lascarina aparentemente está em sofrimento. Sua morte foi provocada pela "mão ladra e cruel de Hades"18 (ANGELOV, 2012, p. 269). Ao prometer se juntar à amada, Láscaris declama que aceitará "a punição de Hades e a aflição da diminuição"19 (ibidi, p. 269). Apesar desta visão negativa que aparece na obra, não é possível concluir que o Hades era um local unicamente de sofrimento para a alma, segundo Láscaris. Para os bizantinos, afinal, a morte era uma consequência do pecado (DENNIS, 2001, pp. 1-7) e a punição no Hades, como uma simples prévia do Julgamento Final na explanação de Bardanes, também seria. Ao longo da obra, Láscaris confessa que viveu uma vida de pecado ao gozar da materialidade corrompida, então não seria de se esperar que fosse recompensado no Hades.

17 A Septuaginta é a principal tradução do Velho Testamento hebreu para o grego, datada aproximadamente ao século III a.C.. Hades era o deus do submundo na mitologia grega, o que deve ter influenciado na escolha de tradução do limbo judaico.

18 No original: "Thieving and cruel hand of Hades ". Talvez uma personificação do Hades, incorporando o deus do submundo da mitologia grega clássica, um exemplo do 'Saber Exterior' bizantino.

19 No original: "The punishment of Hades and the affliction of diminution". 
É importante apontar para o caráter de dor e sofrimento que está na essência da experiência de Láscaris com a morte. No século XIV, o filósofo bizantino Demétrio Cydones (1324-1398) viria a escrever um tratado em que declarava que o medo da morte não era racional, "continuando uma tradição filosófica grega milenar" (ibidi, p. 7). Doravante, "a morte não era o fim da vida, mas uma transformação da vida" (ibidi, p. 7). Com efeito, Láscaris não apresenta medo da morte nos Epítomes Éticos e até pede o fim de sua vida no último ensaio, a fim de ser reunido com a sua falecida esposa. Entretanto, sua experiência com a morte é fundamentalmente negativa. "Viajando pelas alturas da felicidade, recebi ali pela mão da sorte a experiência da inconstância do tempo. Estando, por conta disso, nos picos do luto, aprendi que há coisas valorizadas pelos mortais, mas destruídas pelo tempo, deixando nenhuma glória nelas no final"20 (ANGELOV, 2012, p. 257). Assim ele abre o terceiro ensaio - a morte, extrapolada a partir do falecimento de Elena Lascarina, é uma ruptura na felicidade e geradora de sofrimento, uma consequência nefasta da irregularidade do tempo profano e corruptor.

O luto por Elena Lascarina é o que impulsiona os Epítomes Éticos, mas aquele era, por sua vez, ocasionado pelo intenso amor que Láscaris aparentemente sentia por sua esposa. A linguagem do amor era uma especificidade da religiosidade bizantina, na medida em que "a ardente linguagem do amor físico era aplicada [...] a relações espirituais" (CAMERON, 1997, p. 8), em particular na dinâmica entre o homem religioso e Deus, impensável no cristianismo ocidental. O amor (eros) e a linguagem da sexualidade eram maneiras de se aproximar de Deus e de seu plano sagrado, incluindo, evidentemente, o tempo sagrado de Deus. Se os rituais eram as reatualizações de mitos na lógica do eterno retorno (ELIADE, 1992) ${ }^{21}$, a forma como os bizantinos experimentavam o amor era em si própria uma constante reinserção do bizantino no tempo sagrado. A possível intimidade transcendental a Deus era uma

20 No original: "Journeying on the heights of happiness, I received there at the hands of fortune the experience of time's inconstancy. Dwelling on account of this on the peaks of grief, I learned that there are things valued by mortals but destroyed by time and leaving behind no glory in them in the end".

21 Eliade também escreve que, ao imitar os deuses pelo ritual, o homem "'sai' da duração profana para reunir-se a um Tempo 'imóvel' e à 'eternidade'." (p. 88). 
Tempo e Tempos no Mundo Bizantino do Século XIII: Análise dos Epítomes Éticos sobre a Instabilidade da Vida, de Teodoro II Láscaris

característica particular da teologia bizantina, na forma da "deificação (théôsis) do homem" (ELIADE, 2011, p. 63), e possibilitava esse tipo de elevação ao sagrado. No caso da elevação do amor profano ao amor sagrado, a tese de Orígenes marcava presença:

Sentir desejo (eros) é natural para seres humanos: enquanto seres humanos
desejam muitas coisas ao longo de suas vidas, ele diz, o verdadeiro objeto do
eros é o bem, que também é louvável, e o único desejo louvável é aquele que é
direcionado a Deus. O amor humano, ele sugere, é bom enquanto dirigido a
uma pessoa boa, e é esse tipo de amor que funciona como uma metáfora, ou
como preliminar, para o amor de Deus. De certos tipos de amor humano, é
possível atingir o amor divino. (CAMERON, 1997, p. 11).

Nesse sentido, o amor que Teodoro II Láscaris afirmava sentir por Elena da Bulgária pode ser interpretado como uma forma de deificação do homem, condizente com a teologia bizantina. Era esse amor que permitia ao imperador transcender a inconstância do tempo e superá-la, driblando suas forças destrutivas para unir-se ao tempo sagrado. Ao final do último ensaio, a imperatriz Elena é chamada de "a salvação da minha vida, tanto espiritual quanto corporal"22 (ANGELOV, 2012, p. 269). Essa seria uma das principais razões do sofrimento descrito por Láscaris após a morte da esposa. Seu falecimento representa a condenação da alma de Láscaris à corrupção do tempo profano e até implica em seu desencantamento com a própria ideia de eros no oitavo ensaio, o qual "menciona eros como uma força da natureza humana, descartado aqui como levando a nada permanente e verdadeiramente existente" (ibidi, p. 243).

A oscilação de Láscaris entre o real e o inexistente, entre o tempo profano da destruição e corrupção e do tempo sagrado da permanência e do sentido, é uma clara herança da sistematização parmenidiana do cosmos. Gerald Whitrow nos oferece uma visão sobre a concepção de Parmênides:

Sua proposição básica era: "Aquilo que é é, e lhe é impossível não ser." A partir disto, afirmava que, uma vez que somente o presente é, disto decorre que passado e futuro são igualmente carentes de significado - o único tempo é um tempo presente contínuo, e o que existe é não criado e também imperecível. A

22 No original: "The salvation of my life, both spiritual and corporal". 
partir disto, Parmênides propôs uma distinção básica entre o mundo da aparência, caracterizado pelo tempo e a mudança, e o mundo da realidade, imutável e atemporal. O primeiro é revelado por nossos sentidos, mas estes são enganosos. O segundo nos é revelado pela razão e é o único modo verdadeiro de existência. (WHITROW, 1993, p. 56)

Em última instância, Teodoro II Láscaris, ao compor os Epítomes Éticos, está justamente carente de significado. "Eu lamento e choro na minha mente a na minha alma, porque os assuntos humanos se tornaram dignos de lamentação como inconstantes, inexistentes, inúteis, e não tendo nada que não seja relacionado ao pesar, enquanto tudo é corrompido e se precipita em direção ao míssil da catapulta"23 (ANGELOV, 2012, p. 260), ele escreve no quinto ensaio. No próximo, ele complementa: "comecei a me questionar sobre a decepção da vida, pela qual pessoas criadas para existir são como inexistentes e, portanto, não existem." ${ }^{24}$ (ibidi, p. 261). Láscaris, contudo, elabora um possível escape daquilo que é inexistente logo em seguida, colocando sua fé na capacidade de observação e na razão:

Comecei a me questionar sobre todas essas coisas não porque elas são admiráveis em valor, mas porque são como coisas originais, extraordinárias e longe de necessárias. Toda alma deve então estar pasma com a inconstância dos assuntos humanos, para que, ao estarem pasmos com sua inconstância, possam atingir a constância da virtude [...] por essa razão todos que explicam o conhecimento do existente se maravilham com o tempo, assim como com as corrupções e mudanças causadas pelo tempo, estabelecendo como leis que nenhum deles tem constância e que as decisões de uma alma filosófica são resolutas. ${ }^{25}$ (ibidi, p. 261).

A influência da filosofia grega nas noções de tempo dos Epítomes Éticos também aparece reveladoramente em outras passagens. Com efeito, "a espiritualidade dos Epítomes Éticos é

23 No original: "I mourn and weep in my mind and soul, because human affairs have come to be worthy of lamentation as inconstant, nonexistent, useless, and having nothing that is unrelated to sorrow, while everything is corrupted and rushes toward the missile of the catapult".

24 No original: "I have come to wonder at life's deception, through which people created to exist are as though nonexistent and therefore do not exist."

25 No original: "I have come to wonder at all these things not because they are admirable in value, but as something novel, extraordinary and far from necessary. Every soul must therefore be amazed at the inconstancy of human affairs, so that by being amazed at their inconstancy it may attain the constancy of virtue [...] for this reason also those who explain the knowledge of the existent marvel at time as well as at the corruptions and changes caused by time, laying it down as a law that none of them has constancy, and that the decisions of a philosophical soul are steadfast.". 
Tempo e Tempos no Mundo Bizantino do Século XIII: Análise dos Epítomes Éticos sobre a Instabilidade da Vida, de Teodoro II Láscaris

articulada pelo vocabulário da filosofia natural de Aristóteles: por isso as ideias onipresentes de corrupção, geração, movimento, crescimento e diminuição" (ibidi, p. 242). Noções aristotélicas são predominantes, em especial no décimo primeiro ensaio. Nas palavras do próprio Aristóteles, "não apenas medimos o movimento pelo tempo, mas também o tempo pelo movimento, porque eles se definem um ao outro. O tempo marca o movimento, visto que é seu número, e o movimento marca o tempo" (Aristóteles apud: WHITROW, 1993, p. 57), ideário este recuperado por Láscaris, principalmente em sua máxima "se há natureza, há um início de movimento" ${ }^{26}$ (ANGELOV, 2012, p. 266). Ele continua: "se teve um início, chegaria ao repouso para verdadeiramente manifestar o que a natureza é, isto é, o início do movimento e o repouso"27 (ibidi, p. 266). A ideia de tempo surge aqui na diferenciação entre os estados de movimento e repouso, como em Aristóteles. Segundo Whitrow, para o filósofo grego "é pela consciência do 'antes' e do 'depois', na mudança, que temos a consciência do tempo" (WHITROW, 1993, p. 57), tese também reproduzida por Láscaris, que foi seu ávido leitor e estudioso.

Por último, a fim de melhor compreender os elementos escatológicos presentes nos Epítomes Éticos, elegemos retornar ao início do sexto ensaio:

Alguns já admiraram a glória imperial e outros ansiavam por riquezas e pelos prazeres da luxúria, mas a maioria das pessoas anseiam por tudo - alguns pelos picos da glória, outros pela alegria do dinheiro, e outros ainda pela fácil e imperturbada vida do luxo. Fico impressionado com as opiniões da multidão e com as razões pelas quais ela veio a admirar o que não tem nada de admirável. Fico impressionado, portanto, com o que os admiradores não deveriam admirar. Venho maravilhado com a criação da natureza. Enquanto me maravilho com a criação da natureza, examino coisas nas quais não encontro nada digno de admiração, porque elas também estão sujeitas a morrer. Pois elas são alteradas ao longo do tempo e mudadas por desventuras e não estão muito distantes do inexistente. ${ }^{28}$ (ANGELOV, 2012, pp. 260-261).

26 No original: "If there is nature, there is a beginning of motion", p. 266.

27 No original: "If it had a beginning, it would come to rest in order to make truly manifest what nature is, namely, the beginning of motion and rest.", p. 266.

28 No original: "Some people previously admired imperial glory and others yearned for riches and the pleasures of luxury, but most people yearn for everything-some for the heights of glory, others for the joy of money, and yet 
Láscaris remete a uma temática também explorada no quinto ensaio, na qual "o autor se posiciona como um observador imparcial atônito com as opiniões da multidão e com a inconstância do destino, à luz de seu próprio sofrimento" (ibidi, p. 241). Ele destaca a efemeridade do mundo material e condena sua observação por outros e, consequentemente, por ele mesmo. A conclusão de que tudo o que é alterado é praticamente inexistente e fadado à morte segue o espírito geral da obra.

Aqui, no entanto, a essência do que nos interessa é a primeiríssima passagem, que julga a glória imperial como sendo alterável e corruptível pelas forças do tempo e sujeita ao desaparecimento na mesma categoria do restante citado. Sob um primeiro olhar, essa passagem parece ser insignificante - ou pelo menos não mais ou menos significante do que o resto do conteúdo dos Epítomes Éticos - mas, em verdade, revela uma transformação radical no pensamento e na identidade da sociedade bizantina e certo pioneirismo de Láscaris em sua concepção. Primeiramente é fundamental ressaltar que a identidade bizantina sempre esteve intimamente ligada à cidade de Constantinopla e ao papel cósmico de seu Império dos Romanos no tempo sagrado e no plano de Deus:

Os próprios termos Roma e romano tinham conotação de uma autoridade soberana, legítima e incontestável, invocando o maior império que o mundo já tinha visto até então. [...] Governantes bizantinos ainda encenavam os desfiles triunfais pelas ruas e recrutavam o apoio dos cidadãos para executá-los, manifestando o conceito romano clássico de 'vitória eterna'. (SHEPARD, 2008, p. 5).

Ao universalismo imperial legítimo e à soberania incontestável do imperador se aliavam a concepção religiosa e o destino escatológico do império. "As relações de Bizâncio com os seus vizinhos eram, em última instância, moldadas pela sua consciência de seu destino especial dado por Deus [...] pois a ultima ratio de sua existência era a sua missão cristã e imperial" (HOWARD-JOHNSTON, 2008, p. 954). Com efeito, havia uma espécie de destino

others for the easy and untroubled life of luxury. I am amazed at the opinions of the crowd and at the reasons why it has come to admire what has no share in anything admirable. Amazed therefore at what admirers should not admire, I have come to marvel at nature's creation. As I marvel at nature's creation, I examine things in which I find nothing worthy of admiration because they are also subject to passing away. For they are altered over time and changed by way of misfortunes and are not far distant from the nonexistent". 
Tempo e Tempos no Mundo Bizantino do Século XIII: Análise dos Epítomes Éticos sobre a Instabilidade da Vida, de Teodoro II Láscaris

manifesto bizantino, no qual o império era o principal defensor e promotor do cristianismo e seria não só o centro do mundo profano, como também a ponte necessária entre o profano e o sagrado. De fato, "o império e a capital estavam intimamente ligados ao destino da humanidade" (SHEPARD, 2008, p. 7) - sua queda prematura era inconcebível na escatologia bizantina.

Naturalmente, o saque de Constantinopla pela Quarta Cruzada em 1204 e a subsequente fragmentação política do império apresentaram notórias dificuldades para essa identidade milenar. "Era quase inimaginável que a 'rainha das cidades' caísse. Nas palavras de contemporâneos bizantinos, sua queda foi um 'cataclismo cósmico'" (ANGOLD, 2008, p. 731). Como conciliar a tragédia de 1204 com o papel escatológico do Império dos Romanos em seu eterno triunfo e missão cristã? Apesar da recuperação da capital em 1261, a percepção da decadência imperial foi apenas acentuada no século XIV, com o estado crescentemente débil e reduzido do império. Em termos pragmáticos, não era mais possível reafirmar o destino manifesto dos bizantinos e do seu império supostamente eterno. De fato, a percepção dessa decadência política e sua tradução cultural radicalmente transformadora foi um dos marcos da chamada Renascença paleóloga ${ }^{29}$. Para Teodoro Metochites, ministro chefe de Andrônico II Paleólogo entre 1305 e 1328 e uma das principais vozes desse renascimento, "o império era apenas uma outra entidade política, e seu colapso iminente mais uma manifestação da lei universal da criação e decadência" (SEVCENKO, 2002, p. 291).

Em meados do século XIII, a situação política do Império dos Romanos - ou melhor, do império de Niceia - de Teodoro II Láscaris era similarmente desencorajadora. Apesar de deter uma posição de poder relativo superior aos seus vizinhos do que nos dois séculos seguintes, o inimigo latino ainda ocupava Constantinopla. O exílio bizantino até inauguraria uma ideologia salvacionista na monarquia dos Lascáridas (ANGELOV, 2007), mas a condenação da glória imperial nos Epítomes Éticos por Teodoro II revela que o sentimento decadentista e séculos XIV e XV, sob a égide da dinastia dos Paleólogos, pelo notório bizantinista Steven Runciman. Vide: RUNCIMAN, Steven. The Last Byzantine Renaissance. 1970. 


\section{dossiê}

Hermano do Amaral Pinto Neto

questionador da escatologia tradicional já estava presente, ao menos na mente inovadora de seu autor e de seu círculo erudito. De certa maneira, Teodoro II foi um precursor do novo pensamento bizantino do século XIV; ele foi "um rei filósofo - um intelectual que reuniu em sua corte uma brilhante roda de letrados, cujas realizações constituem a pré-história do renascimento paleólogo das letras" (REINERT, 2002, p. 254). Mesmo após a queda definitiva de Constantinopla para os turcos otomanos em 1453, o patriarca ortodoxo Genádio II estava convencido de que o império logo seria restabelecido (SHEPARD, 2008, p. 7), pois precisaria existir em $1^{\circ}$ de setembro de 1492 (o ano final de 7000 AM do calendário bizantino) - prova da força dessa narrativa escatológica, casualmente e inovadoramente desafiada por Teodoro II Láscaris nos Epítomes Éticos.

\section{Considerações finais}

Este artigo não se pretendeu como uma análise exaustiva dos Epítomes Éticos sobre a Instabilidade da Vida. A obra de Teodoro II Láscaris é muito extensa e rica em suas noções de tempo para ser satisfatoriamente e conclusivamente exaurida no contexto dos nossos parâmetros. Procuramos, contudo, comentar algumas das passagens que nos pareceram mais significativas e interessantes, capazes de prover respostas iniciais para as nossas reflexões. Indagamos sobre a percepção de Láscaris do tempo como agente corruptor, verificamos suas maneiras de experimentar a mortalidade humana e a ponte entre o sagrado e o profano - o existente e o inexistente. Investigamos, também, os indícios da transformação da escatologia bizantina a partir desse período.

Como documento e fonte histórica, no entanto, os Epítomes Éticos são praticamente inesgotáveis. São uma valiosíssima porta de entrada para a mentalidade da intelligentsia bizantina do século XIII, cujo autor também reinava como imperador e tinha preocupações próprias derivadas de seu cargo. Sobretudo, os Epítomes Éticos oferecem vários vislumbres de como a elite intelectual de Niceia e a comunidade grega ortodoxa em geral se relacionavam com o tempo. Poderíamos ainda discutir o "lamento de Heráclito"30 (ANGELOV, 2012, p. 257), Heráclito de Éfeso, que certamente influenciou o pensamento do imperador. 
Tempo e Tempos no Mundo Bizantino do Século XIII: Análise dos Epítomes Éticos sobre a Instabilidade da Vida, de Teodoro II Láscaris

que aparece no terceiro ensaio, ou ainda examinar a presença dos ciclos da natureza na obra - sem dúvidas, são questões interessantes para serem postas aos Epítomes Éticos pelo futuro leitor.

Nos resta, todavia, questionar sobre a real influência da filosofia greco-romana na obra de Láscaris. O bizantinista John Haldon afirma que "o racionalismo helênico e o legado paralelo da literatura clássica sempre viveram em uma coexistência difícil com o antirracionalismo religioso e a piedade fundamentalista da cristandade" (HALDON, 2007, p. 212), mas é crucial assinalar que, principalmente a partir da Quarta Cruzada, "havia surpreendentemente pouca fricção entre o helenismo e a ortodoxia, apesar de sua aparente incompatibilidade" (ANGOLD, 2008, p. 752). Afinal, é difícil negar a notável influência da filosofia grega, em especial, da sistematização de Parmênides no pensamento do cristianismo. Assim, como dizer aonde Atenas acaba e Jerusalém começa? Quais seriam as fronteiras entre o Saber Interior e o Saber Exterior, segundo os bizantinos? Onde se traça a linha nos Epítomes Éticos?

Uma possível resposta se encontra na valorização individual e coletiva dos ditos saberes pertencentes a uma dessas duas categorias. Apesar do crescente poder da Igreja Ortodoxa após o colapso da autoridade imperial seguindo a Quarta Cruzada, os bizantinos se viam voltando cada vez mais para o Saber Exterior, herdado de seus antepassados. Isso se deveu, sobretudo, à progressiva homogeneização étnica e cultural do decadente império, anteriormente multicultural, em torno da figura do grego. Embora os bizantinos nunca abandonassem sua identificação com os romanos, o passado helênico foi gradualmente desassociado do paganismo e começa a integrar a identidade bizantina. O papel do latino ocidental e da Igreja de Roma na alteridade bizantina também não deve ser menosprezado:

O cultivo da sabedoria helênica definiu a elite bizantina culturalmente contra os latinos. Em 1254, houve uma disputa entre intelectuais de Niceia e membros de uma embaixada dos Hohenstaufens. Teodoro II Láscaris presidiu. Ele julgou os nicenos vitoriosos e pensou que isso refletia grande crédito aos helenos. A consciência de um passado helênico se tornou uma parte 
integrante da identidade bizantina, mas a sua expressão era uma reserva de uma elite intelectual. (ibidi, pp. 751-752).

Nesse sentido, principalmente a partir do século XIII, o saber exterior da literatura helenista complementava o saber interior do cristianismo ortodoxo em uma relação simbiótica, embora não desprovida de tensão ${ }^{31}$. Nos Epítomes Éticos, esse diálogo marca a sua presença intensamente. As formas de viver o tempo se misturam, como na apresentação do conhecimento como a salvação da alma ${ }^{32}$, recuperando uma tradição helênica antiga. Ao longo dos ensaios, há diversas referências a episódios mitológicos e autores clássicos, como o próprio Homero e Heráclito de Éfeso, sendo uma linguagem aristotélica que é empregada prevalentemente por Teodoro II Láscaris. Entretanto, a moral e as preocupações do autor nos Epítomes Éticos, ao longo de toda a obra, permanecem fundamentalmente cristãs.

\section{Referências bibliográficas:}

ANGELOV, Dimiter. "The Moral Pieces by Theodore II Laskaris". Dumbarton Oaks Papers, pp. 237-269, nº 65-66, 2011-2012.

. Imperial Ideology and Political Thought in Byzantium, 1204-1330. New York: Cambridge University Press, 2007.

ANGOLD, Michael. "The Greek Rump States and the Recovery of Byzantium". In: SHEPARD, Jonathan. The Cambridge History of the Byzantine Empire c. 500-1492. Cambridge University Press, 2008.

ANGOLD, Michael; WHITBY, Michael. "Historiography". In: JEFFREYS, Elizabeth; HALDON, John; CORMACK, Robin (ed.). The Oxford Handbook of Byzantine Studies. Oxford University Press, 2008.

BRYER, Anthony. "Chronology and Dating". In: JEFFREYS, Elizabeth; HALDON, John; CORMACK, Robin (ed.). The Oxford Handbook of Byzantine Studies. Oxford University Press, 2008.

31A tensão explodiu na chamada controvérsia hesicasta, que mobilizaria a vida social, cultural e religiosa dos bizantinos em meados do século XIV. Liderados pelos monges do Monte Atos e pela figura de Gregório Palamas, os hesicastas entraram em confronto com os humanistas bizantinos, representados pelo monge Barlaão da Calábria. O hesicasmo prevaleceu e botou um fim ao renascimento da filosofia platônica em Bizâncio (ELIADE, 2011, pp. 204208).

32 Evidenciado, por exemplo, na passagem do nono ensaio "Portanto toda alma nobre prefere as coisas intelectuais, ao invés das corruptíveis" (ANGELOV, 2012, p. 264). No original: "Therefore every noble soul keeps to intellectual rather than corruptible things". 
Tempo e Tempos no Mundo Bizantino do Século XIII: Análise dos Epitomes Éticos sobre a Instabilidade da Vida, de Teodoro II Láscaris

CAMERON, Averil. "Sacred and Profane Love: Thoughts on Byzantine Gender". In: JAMES, Liz (ed.). Women, Men and Eunuchs. Gender in Byzantium. Routledge, 1997.

COMNENA, Anna. The Alexiad. Tradução de Elizabeth A. S. Dawes. Cambridge, Ontario: In parentheses Publications, 2000.

DENNIS, George T.. "Death in Byzantium". Dumbarton Oaks Papers, pp. 1-7, Vol. 55, 2001.

ELIADE, Mircea. O Sagrado e o Profano. A essência das religiões. São Paulo: Martins Fontes, 1992. . História das Crenças e das Ideias Religiosas. Volume III: de Maomé à Idade das Reformas. Rio de Janeiro: Zahar, 2011.

HALDON, John. Byzanz. Geschichte und Kultur eines Jahrtausends. Tradução de Harald Ehrhardt. Düsseldorf: Patmos Verlag, 2007.

HOWARD-JOHNSTON, James. "Byzantium and its neighbours". In: JEFFREYS, Elizabeth;

HALDON, John; CORMACK, Robin (ed.). The Oxford Handbook of Byzantine Studies. Oxford University Press, 2008.

MACRIDES, Ruth. George Akropolites. The History. Introduction, Translation and Commentary. New York: Oxford University Press Inc., 2007.

MACRIDES, Ruth; MUNITIZ, J.A.; ANGELOV, Dimiter. Pseudo-Kodinos and the Constantinopolitan Court: Offices and Ceremonies. Farnham: Ashgate Publishing Limited, 2013.

MARINIS, Vasileios. Death and Afterlife in Byzantium: The Fate of the Soul in Theology, Liturgy, and Art. Cambridge, 2017.

REINERT, Stephen. "Fragmenation (1204-1453)". In: : MANGO, Cyril (ed.). The Oxford History of Byzantium. 2002.

RUNCIMAN, Steven. The Last Byzantine Renaissance. 1970.

SEVCENKO, Ihor. "Palaiologan Learning". In: MANGO, Cyril (ed.). The Oxford History of Byzantium. 2002.

SHEPARD, Jonathan. "Approaching Byzantium". In: . The Cambridge History of the Byzantine Empire c. 500-1492. Cambridge University Press, 2008.

WELLS, Colin. De Bizâncio para o mundo. A saga de um império milenar. Tradução de Pedro Jorgensen. Rio de Janeiro: Bertrand Brasil, 2011.

WHITROW, G. J.. O Tempo na História. Concepções sobre o Tempo da Pré-História aos Nossos Dias. Tradução de Maria Luiza X. de A. Borges. Rio de Janeiro: Jorge Zahar Ed., 1993. 